\title{
Teaching children: the weightiness of adopting practical approach to teaching children
}

\author{
Achmad Kholili \\ Department of English, UniversitasZainul Hasan Genggong, Indonesia \\ achmadkholili93@gmail.com \\ *) correspondence: achmadkholili93@gmail.com
}

\begin{abstract}
Teaching children still becomes a challenging task today and copying with that is quite necessary. Although the strategies have been implemented to be successful language learning for the children, however, it sometimes still fails due to lack of several practical approaches in the teaching process. This paper is presented to shed light on some practical approaches to teaching English to young learners. It covers intellectual development, attention span, sensory input, affective factors, and authentic meaningful language. These approaches are offered so as to make the goal of learning attainable. The teachers are strongly recommended to apply this in English language teaching to their children.
\end{abstract}

Keywords: Teaching children, practical approaches, and learning goal

\section{INTRODUCTION}

Teaching children is subsumed under something necessaryin learning English. It is based on the statements issued by some experts since children have innate faculties. These days, there have been quite a few teachers of English both EFL and ESL teachers conducting English teaching to the children. A wide range of strategies is used by the teachersto teach thembut they do not take into adequate consideration for several practical approaches of teaching them. Therefore, they are not likely established in teaching the language to them. It will subsequently not come to fruition in learning if thoseapproaches are not applied in teaching the language for the children.

There are some reasons why the teachers should know those approaches. As has been stated by Brown (2015:108) even if you could somehow pack a suitcase full of the most current teaching resources, you would still have to face the question of who your learners are, wherethey are learning, and why they are learning. This statement is affirmatively meaningful that although teachers have developed some strategies or have used teaching resources for teaching the children a language, it will not be completely fruitful if they do not recognizewho they teach, where they teach, and why they are learning. Therefore, in addition to knowing the teaching resources or strategies of teaching the children, the teachers must also know few practical approaches for teaching them for the sake of successful learning. A case in point is that the children have learned vocabulary by a teacher. In the meantime, the teacher has used collaborative learning to teach them. However, the teacher seems very confusedsince the students encounter difficulties to learn the language because the teacher does not take into account of who they teach. In fact, he is teaching children in this session.

This example emphasizes us that the teacher should know severalintegrated approaches so as to be effective teaching. Since this is the case, the writer wants to point up that there are few approaches that may be used to teach the children. Brown (2015:110) states that to successfully teach children a second language requires specific skills and intuitions that differ from those appropriate for adults teaching. The integrated approaches comprise Intellectual Development, Attention Span, Sensory Input, Affective Factors, Affective Factors, as well as Authentic and Meaningful Language. The writer, in this case, also wants to assert that teaching the children is different from adults. Hence, Brown points out the statement. 


\section{AchmadKholili}

This paper aims at clarifying several practical approaches of teaching children since the approaches are at times neglected in teaching a language to them. Much consideration for the practical approaches in teaching the children is of great important in this session. Therefore, several subsequent approaches may be developed in teaching them.

\section{METHODS}

This paper aimed at clarifying several practical approaches of teaching children since the approaches are at times neglected in teaching a language to them, this study was undertaken at an elementary school as young learners. Then it focused on investigantingintellectual development, attention span, sensory input, affective factors, and authentic and meaningful language through class observation. All of the data was described descriptively.

\section{RESULTS AND DISCUSSION}

Seeing a number of teachers of children are nowadays available, the significance of developing some practical approaches is of essential. Brown (2015:110) five categories help gives some practical approaches to teaching children. They are intellectual development, attention span, sensory input, affective factors, and authentic and meaningful language.

\section{Intellectual Development}

Each person has ability, so do the children. However, the ability children have is not similar to the adult. Piaget (1972) in Brown called "concrete operation", we need to remember their limitation, rules, explanations, and other even slightly abstract talk about language must be approached with extreme caution (Brown, 2015: 110). The intellectuality of the children in this case is different from adults. The children have intellectual stage up to the age of eleven. Therefore, the teacher teaching children should take this into account. The children in this stage have little acquaintance for "correctness". The teacher may teach the students a variety of concepts or chapters. However, the children will not be successful in learning the concepts if the teachers do not ponder their intellectual limitation. In this case, the teacher should assist the children's cognitive development. According to Brown (2015:110) there are some guidelines for teaching children: cognitive development. They are clarified as follows:

1. Do not explain grammar using terms like "present progressive" or 'relative clause".

2. Rules stated in abstract terms ("to make a statement into a question, you add a doordoes") should be avoided.

3. Some grammatical concepts, especially at the upper levels of childhood, can be called to learners' attention by showing them certain patterns ("Notice the ingat the end of the word") and examples(This is the way we say it when it is happening right now. "I'm walking to the door").

4. Certain more difficult concepts or patterns require more repetition than adult needs, but not to the point of boredom! Short, snappy drills may be very helpful

5. But when you do short drills, make sure your students understand the meaning and relevance of what they are reciting. Try to avoid scenes like the one with the little boy who had no pencil.

E.g.a teacher teaches the students color, that is, red. The teacher, in this case, provides the students with some examples of colors, but the teacher explains that the red color is only in the right side, whereas in the left side is not. The right side belongs to red, whereas the left one belongs to blue. This teaching requires more repetition to make the children remember on.

\section{Attention span}

The second thing which is salient to recognize is the attention span. According to oxford dictionary at en.oforddictionaries.comclarifies that attention span is the length of time for which a person is able to 
concentrate on particular activity or subject.Another statement is also pointed out with Wikipedia at wnw.wikipedia.com, that is, Attention span is the amount of concentrated time one can spend on a task without becoming distracted. Most educators and psychologists agree that the ability to focus and sustain attention on a task in crucial for the achievement of one's goals. It is important to understand what attention span means. Since language lessons can at times be difficult for children, the teachers' job is to make them interesting, lively, and fun. How do you that?

Brown (2015:113) clarifies several hints to teach the children. The following might be considered in teaching them,

1. Because children are focused on the immediate here and now, activities should be designed to capture their immediate interest.

2. A lesson needs a variety of activities to keep interest and attention alive.

3. A teacher needs to be animated, lively, and enthusiastic about the subject matter. Consider the classroom a stage on which you are the lead actor; your energy will be infections. While you may think that you're overdoing it, children need this exaggeration to keep spirit buoyed and minds alert.

4. A sense of humor will go a long way to keep children laughing and learning. Since children's humor is quite different from adults', remember to put you in their shoes.

5. Children have a lot of natural curiosity. Make sure you tap into that curiosity whenever possible, and you will thereby help to maintain attention and focus.

It is also stated in another article that humor is not separated when teaching to the children.Asian students can be notoriously serious and focused, but that doesn't mean that they don't have a funny bone. If you can incorporate activities that stress fun and competition without too much forced language practice, you will have found one key to success (in How to Young Learners' magazine).

E.g. a teacher teaches the children about animal. To make the activity interesting, the teacher may provide them with some examples of animal, for example, the animal is a cat. The teacher may say this animal is a cat. He mayimitate to say the same sound as the cat, "Meoong, Meoong, Meoong". Thus, "if you find it somewhere, that's called as a Cat", he says to the children. This activity is clear that the teacher must not only explain and give the examples of the cat, but also gives the practice for the sound of a cat so as to make the students interested in and focused on learning the sort of the animal. Therefore, the children will raise their attention span (concentration). They will automatically focus and concentrate on what they are learning. This is important for the sake of successful learning.

\section{Sensory Input}

Children need to have all five senses stimulated. Your activities should strive to go well beyond the visual and auditory modes that we feel are usually sufficient for a classroom (Brown: 2000:89).

The following is the guidelines for teaching children: Sensory input

1. Pepper your lessons with physical activity, such as having students act out things (role-play) play games, or do Total Physical Response activities.

2. Projects and other bands-on activities go a long way toward helping children, are excellent ways to get them to learn words and structures and to practice meaningful language.

3. Sensory aids here and there help children to internalize concepts. The smell of flowers, the touch of plants and fruits, the taste of foods, liberal doses of audiovisual aids like videos, pictures, tapes, music-all are important elements in children's language teaching.

4. Remember that your own nonverbal language is important because children will indeed attend very sensitively to your facial features, gestures, and touching.

E.g. the children learn about family. The teacher introduces some family member name. Then, to make the students understand well, the teacher also provides with audiovisual aids, he provides with a video introducing family trees. It will be of beneficial to them so that they could be more comprehended. 


\section{AchmadKholili}

\section{Affective Factors}

A common myth is that children are relatively unaffected by the inhibitions that adults find to be a block to learning. Teachers need to help them to overcome such potential barriers to learning. (Brown, 2015:113).The following is the guidelines for teaching children: Affective factors.

1. Help your students to laugh with each other at various mistakes that they all make.

2. Be patient and supportive to build self-esteem, yet at the same time be firm in your expectations of students.

3. Elicit as much oral participation as possible from students, especially the quieter ones, to give them plenty of opportunities for trying things out.

E.g. the children learn about the pronunciation in English, then one of the students commits error in pronouncing a word, for example, "bathroom". In fact, he should say "Bedrom" but he say "Batrom". This may make the student unconfident to repeat the word. As a result, he feels shy to redo it. The teacher may support him in order that the student may have willingness to try it again. The teacher may also consider other students who are withdrawn or reserved in learning the pronunciation. The teacher may give more opportunities for them to try to pronounce the word.

\section{Authentic, Meaningful Language}

Brown (2000: 90) points out those children are focused on what this new language can actually be used for here and now. Your classes can ill afford to have an overload of language that is neither authentic nor meaningful.The following is the guidelines for teaching children: Authentic, Meaningful language

1. Children are good at sensing language that is not authentic; therefore "canned" or stilted language will likely be rejected.

2. Language needs to be firmly context embedded. Story lines, familiar situations and characters, real-life conversations, meaningful purposes in using language-these will establish a context within which language can be received and sent and thereby improve attention and retention. Context-reduced language in abstract, isolated, unconnected sentences will be much less readily tolerated by children's minds.

3. This statement is also emphasized by Susan (1992:27) that we won't help the children to develop their capacity to concentrate if we jump into inconsequently from one topic to the next.

4. A whole language approach is essential. If language is broken into too many bits and pieces, students won't see the relationship to the whole. And stress the interrelationships among the various skills (listening, speaking, reading, and writing), or they won't see important connections.

E.g. teacher teachesthe children a story. He take one of the stories, for example, "Cat and Mouse", the story is taken out due to the fact that it is interesting and easy to comprehend. However, after the teacher tells the story, the children have difficulty comprehending the story since the teacher uses unconnected sentences and does not recount it in sequence. It then makes the students get into bad mood even though the story is quite intriguing. This should be avoided. The teacher must be able to tell the story not only in context-embedded but also in connected-sentences so as to be meaningful and easy to grasp by the children.

\section{CONCLUSION}

Since the approaches have been clarified above, the writer finally draws a conclusion that the availability of the approaches is of essential to be applied in teaching English to the children. The teacher might be ableto use a wide range of strategies to teach their pupils but the result will not be fully successful if not balanced with the practical, integrated approaches above. Therefore, the approaches are very suggested to the teachers who teach English to the children. This is important to know since the children are different from adults. The limitation of the children should be recognized by developing the practical approaches. Hence, taking the approaches for teaching 
English to the children iscompulsory in this case. Those aim at making successful learning in English.

\section{REFERENCES}

Brown.H. Douglas. 2000. Teaching by Principles: An Interactive to Language Pedagogy. $4^{\text {th }}$ Ed. New York: Longman.

Brown. H. Douglas. 2005. Teaching by principles: An Interactive to Language Pedagogy. $4^{\text {th }}$ Ed. New York: Longman.

Halliwel.S.1992. Teaching English in the Primary Classroom. New York: Longman Group UK Limited

Oxford. D. 2017. Attention Span. en.oforddictionaries.com/attentionspan. Accessed September 12 ${ }^{\text {th }}$, 2019. 